\title{
Avaliação das políticas habitacionais na Região Metropolitana de Londrina-PR
}

\author{
Appreciation of housing policies in the Metropolitan Area of Londrina-PR
}

\author{
Elisa Roberta Zanon* \\ Sandra Maria Almeida Cordeiro** \\ Miguel Etinger de Araujo Junior***
}

\begin{abstract}
Resumo:
O artigo apresenta a interpretação de resultados parciais da pesquisa "Direito à Moradia: aplicabilidade e efetividade dos instrumentos jurídicos na Região Metropolitana de Londrina-PR" iniciada em 2012 pela Universidade Estadual de Londrina. O contexto da produção de habitação de interesse social em Londrina, a partir dos anos 1980, fornece subsídio de análise e reflexão sobre a operacionalização da política de habitação de interesse social no município, com destaque para os programas da década de 2000 , em especial com a implantação do Residencial Vista Bela, pelo Programa Minha Casa Minha Vida, um dos maiores conjuntos habitacionais do Brasil, entregue à população nos anos 2011 e 2012.
\end{abstract}

Palavras-chave: Habitação de interesse social. Direito à moradia. Programa minha casa minha vida. Londrina/PR.

\begin{abstract}
This paper presents the interpretation of partial search results on the "Right to Housing: applicability and effectiveness of legal instruments in the Metropolitan Area of Londrina-PR" since 2012 in the Universidade Estadual de Londrina. The context of social housing production in Londrina, from the years 1980 provides analysis allowance and reflection on the implementation of social housing policy in the city, especially in the 2000s programs, in particular with the implementation of the Residential Vista Bela by Minha Casa Minha Vida Program, one of the largest housing projects in Brazil, handed out the population in 2011 and 2012.
\end{abstract}

Key-words: Social housing. Right to housing. Minha casa minha vida program. Londrina/PR.

\section{Introdução}

Em pleno século $\mathrm{XXI}$, as cidades estão imersas nas relações estabelecidas pela globalização e mudanças estruturais no capitalismo. Contraditoriamente, sua população

\footnotetext{
* Arquiteta. Universidade Estadual de Londrina. Mestre em Geografia: Dinâmica Espaço Ambiental pela UEL. Professora do Departamento de Arquitetura e Urbanismo da UEL. E-mail: lisazanon@yahoo.com.br

** Assistente Social. Mestre e doutora em Serviço Social pela UEL. Professora do Departamento de Serviço Social da UEL. E-mail: sandra.cordeiro@sercomtel.com.br

*** Advogado. Mestre em Direito Público e Evolução Social pela Universidade Estácio de Sá. Doutor em Direito da Cidade também pela UERJ. Professor do Departamento de Direito Público da Universidade Estadual de Londrina. E-mail: etinger@gmail.com
} 
vive na precarização das relações trabalhistas ao mesmo tempo que a revolução tecnológica e informacional traz outro significado à vida no espaço urbano, principalmente, pelas relações que se compõem em territórios. O crescimento urbano, inevitável a esta contemporaneidade, apresenta-se na fragmentação da cidade que também revela uma organização intraurbana segregada social e espacialmente.

Remetendo ao Brasil, as cidades são bastante diferenciadas pelo seu porte, densidade populacional, atividades econômicas, bem como sua formação social e cultural, porém, ao falar de desenvolvimento, este ocorre via de regra de modo desigual. Os contrastes são construídos pelos diversos agentes produtores do espaço, que além de imobiliaristas, construtoras, o próprio Estado se apresenta como diretor responsável. No caso da habitação de interesse social, a atribuição de tutela do Estado, quando cumprida, é feita aos montes, dentro de uma regra que foge da plena inserção urbana e aos direitos à cidade. Em Londrina, as condições são semelhantes, sendo que neste artigo apresentase uma reflexão da produção de habitação de interesse social a partir dos anos 1980, com foco nos processos espaciais recentes da década de 2000 e início da década de 2010, especificamente com a implantação de 2.712 unidades habitacionais do Residencial Vista Bela, localizado nas franjas da zona norte da cidade e entregue à população entre os anos 2011 e 2012 pelo Programa Minha Casa Minha Vida (PMCMV) de âmbito nacional.

Os assuntos abordados neste artigo compõem parte da pesquisa realizada pelo Projeto de Pesquisa "Direito à Moradia: aplicabilidade e efetividade dos instrumentos jurídicos na Região Metropolitana de Londrina-PR" pela Universidade Estadual de Londrina iniciado em 2012, cujo objetivo consiste em analisar as bases de dados existentes sobre os aspectos da política e da produção habitacionais de Londrina e de Cambé, município que faz parte da Região Metropolitana de Londrina, buscando ao final contribuir para uma melhor atuação do Estado e da sociedade. Em Londrina, o projeto tem como campo de pesquisa o Residencial Vista Bela, onde a aquisição da propriedade foi subsidiada. O projeto encontra-se atualmente na fase de conclusão de aplicação de questionários e entrevistas no Residencial Vista Bela, em que as perguntas objetivas, baseadas no conceito de direito à moradia adequada, foram respondidas pelos moradores solicitados, envolvendo vários parâmetros: a segurança jurídica da posse, a qualidade da construção, o acesso à 
infraestrutura (esgoto, saneamento, coleta de lixo), o acesso a serviços sociais públicos e a inserção econômico-social.

Tendo como fundamentação que o direito à moradia é um direito constitucional e social, as políticas públicas municipais e demais esferas de governo devem promover a moradia digna, o que, no caso de Londrina, constatou-se até o momento que as necessidades habitacionais de modo pleno não são atendidas, principalmente quando se trata da inserção urbana.

\section{Breve contexto da questão da moradia no Brasil}

No histórico geral, a questão da habitação como problema da cidade remonta a Idade Contemporânea, no século XVII, início da industrialização ocorrido na Inglaterra. Engels (1982) polemiza em sua publicação na Alemanha em 1873 Para a questão da habitação, em que apresenta fatos decorrentes da industrialização do século XVIII, resultando no crescimento urbano que expandiu as cidades e afetava principalmente a classe trabalhadora na Inglaterra. Segundo Engels (1982), os trabalhadores ganhavam baixos salários e viviam em condições precárias de moradia, com a aglomeração de pessoas nas cidades em condições insalubres de sobrevivência, decorrendo disso diversas epidemias, agravando ainda mais a crise da habitação. Diante desse contexto, deu-se início às manifestações para controle da crise, porém, foram ações voltadas para a questão sanitária, devido às epidemias e não para o problema da habitação em si. Desse modo, Engels (1982) enfatiza que a falta de habitação é necessariamente produzida por uma sociedade segmentada e burguesa.

Para o capitalismo, se a questão da habitação é uma estratégia da ideologia da sociedade, a premissa básica é o lucro incessante, que se utiliza de todos os subterfúgios possíveis para continuar com sua lógica. Tem-se constatado cada vez mais o Estado isento de sua responsabilidade em possibilitar o acesso à moradia digna relegando a uma parcela mínima da sociedade em ter que buscar esse direito via mercado, ou seja, tendo que comprar uma casa, e com isso sendo obrigado a alimentar o capital financeiro. Com a expulsão dos trabalhadores de suas terras, esses buscaram formas de atender a sua subsistência. A partir disso, reposiciona-se a análise dos elementos de constituição da cidade e do urbano, compreendendo o que Santos (1985, p. 49) afirma: "[...] a sociedade 
só pode ser definida através do espaço, já que o espaço é o resultado da produção, uma decorrência de sua história - mais precisamente, da história dos processos produtivos impostos ao espaço pela sociedade".

Na interpretação de Santos (1985), o espaço é uma atividade produtiva, tornando-se assim algo que tem valor de uso e valor de troca, como uma mercadoria. Esse processo lento e progressivo de produção da moradia contribui com a acumulação capitalista e serve de exemplo para desvendar um dos paradigmas do ambiente urbano.

No Brasil atual, Pelegrino (2003) afirma que as fraturas sociais, políticas e espaciais tecidas ao longo da formação social expressam-se na precariedade das moradias, no mercado informal de trabalho e, sobretudo, na ausência de perspectiva de futuro para os segmentos pauperizados. Desse modo, o déficit habitacional, hoje constatado nas grandes cidades brasileiras, tem uma larga história pretérita, sendo que a intervenção do Estado para promover política de habitação se mostrou ineficaz, visto que não dava conta de atender a demanda da população que necessitava de acesso no país. Na verdade, esse tem sido um espaço de reprodução das desigualdades sociais e de perpetuação de privilégios.

Para o autor supracitado, o processo de construção e desenvolvimento das cidades brasileiras sempre ocorreu de modo refratário à circulação e à permanência dos segmentos pauperizados. Ainda segundo Pelegrino (2003), a questão espacial emerge nas primeiras experiências de divisão do território, no sentido físico, realizado pelas expedições de conquista e de colonização. Encontramos na literatura que essa divisão, da distribuição das terras, ocorreu segundo os interesses da Coroa Portuguesa. A despeito das formas sociais preexistentes e dos conflitos ocorridos com as populações nativas e outros invasores, os colonizadores iniciaram o ordenamento do território por meio da construção das primeiras vilas e cidades, sempre no litoral, imprimindo a marca da desigualdade social e da segmentação territorial. Tal marca, ainda, continua expressiva frente as precárias condições de moradia e trabalho para a população menos favorecida nas grandes cidades brasileiras. Nesse sentido, mesmo que o processo de urbanização tenha ocorrido de modo mais amplo durante o regime republicano já no século $X X$, o peso das heranças colonial e escravista permanece notável também na formação das cidades brasileiras.

No clássico Os Donos do Poder, tese desenvolvida por Raymundo Faoro (2001), a origem do patrimonialismo brasileiro fica caracterizada pela relação entre concentração de 
patrimônio, poder econômico e poder político. Além de ser condição para a concentração de poder, o patrimonialismo se explica pela captura da esfera pública por interesses privados. A formação da sociedade brasileira ainda pode ser "lida" na realidade urbana: a "política do favor" (ou clientelismo); o "homem cordial" (aversão ao enfrentamento objetivo e impessoal de conflitos); o "trabalho como maldição" (desrespeito e desprestígio do trabalho); a "tradição livresca e discursiva" (leis e planos que não se implementam: discurso distante da prática); e a "tradição de mimetismo cultural" e das "ideias fora do lugar" (deslocamento entre ideário e estrutura produtiva), como expõe Maricato (2008).

Nabil Bonduki (1998), um dos autores que estudou a relação entre o processo de formação das cidades brasileiras e a cultura política, afirma que a desigualdade social das cidades tem suas causas nas formas com que se organizou a sociedade, na maneira com que se construiu o Estado Brasileiro, marcado pelo patrimonialismo advindo das consequências da Lei de Terras de $1850^{1}$, no qual se confundem o interesse público e o privado, nas dinâmicas de exploração do trabalho impostas pelas elites dominantes desde a colônia e, principalmente, no controle absoluto dessas elites sobre o processo de acesso à terra, tanto rural quanto urbana. Assim, nas cidades, a trajetória da política social de habitação, como questão da moradia, apresenta-se permeada pela vinculação com questões estruturais da sociedade e pelas singularidades conjunturais que culminaram no agravamento das desigualdades.

Atualmente, o Brasil é considerado um país predominantemente urbano, e, de acordo com o Instituto Brasileiro de Geografia e Estatísticas (IBGE, 2010), a taxa de urbanização passou de 44,7\% no Censo de 1960 para 84,4\% em 2010. Numa análise mais apurada da realidade brasileira, constata-se que a população urbana se concentra em poucas grandes cidades, sendo que na maioria dos municípios prevalesce as características de pequeno porte. Na verdade, no Brasil não há definições muito claras acerca do número mínimo de habitantes para definir cidade, como expõe Dambros (2014, p. 13) em que "o conceito de cidade adotado pelo IBGE define que qualquer comunidade urbana caracterizada como sede de município é considerada uma cidade, não importando o seu

\footnotetext{
${ }^{1}$ A chamada Lei n. 601 ou Lei de Terras, de 1850, estabeleceu um novo modo de organização da propriedade privada no Brasil para a regulamentação da posse de terras, tornando a compra como a única forma de acesso à terra, ao mesmo tempo que abolia, em definitivo, o processo de doação de terras por meio do regime de sesmarias. A lei trouxe grandes modificações sociais e econômicas ao país.
} 
número de habitantes". De acordo com o IBGE (2010), dos 5.561 municípios existentes, somente 94 são aglomerados metropolitanos (quando uma cidade funde-se espacialmente com outra, sem perder sua identidade política), com mais de um milhão de habitantes, e apenas 224 municípios concentram $60 \%$ de toda a população brasileira (FERREIRA; UEMURA, 2009). Outro dado importante desse contexto é que os municípios pequenos, com até 20.000 habitantes, representam $73 \%$ dos municípios brasileiros, os quais apresentam $45 \%$ de sua população vivendo em áreas rurais. Ocorre que as cidades brasileiras cresceram marcadas pela ausência de planejamento urbano e/ou pelo favorecimento dos interesses das elites dominantes e permeadas de contradições e de desigualdades sociais e são frutos dos déficits sociais acumulados, por décadas de governos descomprometidos com os interesses da maioria da população.

Mesmo frente a todas essas disparidades sociais e espaciais é de responsabilidade do Estado a formulação de políticas que venham promover o acesso da população menos favorecida à habitação de interesse social, pois parte-se do princípio de que a propriedade urbana deve cumprir com sua função social, a fim de evitar a ociosidade de terrenos ao passo que outros não têm moradia.

\begin{abstract}
A função social da cidade e a função social da propriedade se concretizam, dentre outras formas, nos contornos definidos pela Constituição e demais legislação infraconstitucional. O direito social (fundamental) à moradia, a sua vez, terá maiores condições de ser efetivado quando a propriedade e a cidade cumprem sua função social. Para isso, é imprescindível a atuação do Estado, seja por meio da regulação e aplicação dos institutos previstos no Estatuto da Cidade, seja por meio do estabelecimento de políticas voltadas à ampliação da infraestrutura e dos serviços urbanos, assim como de políticas relativas a projetos habitacionais e de regularização fundiária (CORDEIRO, 2015, p. 33).
\end{abstract}

Nesse sentido, o princípio da função social da propriedade torna-se a base que sustenta os programas habitacionais, a fim de promover a inserção da população que carece de tal tutela. Numa retrospectiva histórica, o BNH (Banco Nacional da Habitação) que vigorou entre os anos 1964 a 1985 pode ser considerado o principal agente produtor dos conjuntos habitacionais realizados no Brasil no século $X X$, ao passo que a implementação de moradia social foi contraditória em termos de atendimento das necessidades plenas da habitação. 
Após o encerramento do $\mathrm{BNH}$, poucos programas tiveram difusão semelhante, retornando no final da década de 2000 com Programa Minha Casa Minha Vida. Valença (2001), em sua obra Globabitação: sistemas habitacionais no Brasil, Grã-Bretanha e Portugal, bem como Arretche (2002), com a publicação Federalismo e Relações Intergovernamentais no Brasil: a reforma de Programas Sociais, partem da ideia de que uma política federal de habitação não se estruturou após a extinção do BNH, e que somente após dez anos, segundo Arretche (2002), é que se alterou o paradigma da política habitacional, quando se introduziu claramente princípios de mercado na provisão de habitação. Além de se ampliar a participação do setor privado, o novo paradigma previa a descentralização da alocação dos recursos federais e a introdução de uma política para o mutuário.

A década de 2000 no Brasil é marcada pela criação do Ministério das Cidades em 2003 e várias leis e programas que passaram a incidir sobre a produção do espaço das cidades. Maricato (2011) destaca o lançamento do Programa de Aceleração do Crescimento (PAC1) em 2007 pelo governo federal², que mantinha um diálogo com o desenvolvimento urbano, sendo destinados recursos para ações de urbanização de favelas. Cordeiro (2015, p. 117) destaca que "dois anos depois (2009), o governo federal lança o Programa Minha Casa Minha Vida (MCMV), calcado na produção de grande número de moradias, ignorando os eixos estratégicos pensados no âmbito do PlanHab, sobretudo no que diz respeito às estratégias urbano-fundiárias". O programa foi aprovado pela Lei Federal no. 11.977/2009 (BRASIL, 2009), que "dispõe sobre o Programa Minha Casa, Minha Vida - PMCMV e a regularização fundiária de assentamentos localizados em áreas urbanas" para a construção de unidades habitacionais, sendo viabilizado pelo Fundo de Arrendamento Residencial (FAR) com recursos transferidos do Orçamento Geral da União (OGU). A medida foi tomada para atender ao déficit habitacional urbano para famílias com renda até $\mathrm{R} \$ 1.600,00$, considerando a estimativa da Pesquisa Nacional por Amostra de

\footnotetext{
2 Criado em 2007, o Programa de Aceleração e Crescimento - PAC é uma política pública criada pelo governo federal, no segundo mandato do presidente Lula, com o intuito de promover a recuperação do planejamento e execução de grandes obras de infraestrutura social, urbana, logística e energética do país. Programa do governo que se propõe acelerar o crescimento econômico, o aumento do emprego e a melhoria das condições de vida da população brasileira.
} 
Domicílios (PNAD), de 2008. Sobre o PMCMV, Cordeiro $(2015$, p.117) traz uma breve descrição da lógica de produção das unidades habitacionais.

\begin{abstract}
Desta forma, emerge a preocupação com o fator locacional da produção habitacional pelo PMCMV, uma vez que a localização passa a ser, muitas vezes, definida pelos agentes do mercado imobiliário, seguindo a sua própria lógica de otimização dos recursos e não a do direito à cidade. Em pouco tempo do programa tem sido inúmeros os exemplos de comparação entre o PMCMV e a política habitacional executada pelo Banco Nacional de Habitação (BNH). O Programa tem reproduzido a lógica dos grandes conjuntos habitacionais em áreas distantes do centro da cidade, promovendo assim a segregação socioespacial.
\end{abstract}

Logo, o lançamento do Programa Minha Casa Minha Vida, no início de 2009, além de alavancar a construção de moradias em grande escala "respondeu a essas dificuldades e garantiu a continuidade de um novo patamar de acumulação na produção imobiliária residencial no Brasil" (MARICATO, 2011, p. 63).

A seguir apresenta-se a trajetória da habitação de interesse social em Londrina, focando um novo bairro inaugurado em 2011 e que nasceu por meio do Programa Minha Casa Minha Vida (PMCMV) no município.

\title{
Londrina: o poder público local e a produção de habitação de interesse social
}

Londrina surgiu em 1929, como primeiro posto avançado para comercialização dos lotes da CTNP (Companhia de Terras Norte do Paraná), sendo elevada a condição de município em 1934, tendo daí em diante um crescimento populacional elevado, o que em décadas depois se tornou ponto de referência do Norte do Paraná, chegando ao século XXI com uma população de 506.701 habitantes (IBGE, 2010).

Com o rápido crescimento populacional concomitante à expansão urbana, o poder público local estabeleceu regras de ordenamento e ocupação da cidade. E aqui outro elemento é demarcado para o direcionamento da expansão urbana que se vinculava à política habitacional. Com a institucionalização do BNH (Banco Nacional de Habitação) no ano de 1964, as questões de moradia foram implementadas por meio de programas habitacionais, e no ano de 1965 foi fundada a Companhia Habitacional de Londrina COHAB/LD para viabilizar a habitação social em Londrina. 
Na década de 1970 houve um forte crescimento da população urbana de Londrina, oriunda do intenso processo de êxodo rural. Segundo dados do IBGE (1983), a população total no censo de 1970 era de 228.532 habitantes, sendo que a população urbana representava $68,41 \%$. Já no censo de 1980 a população total passou para 301.749 , o que perfazia $85,6 \%$ da população urbana. E, nesse contexto, a demanda habitacional já era considerável. Foi então que os primeiros conjuntos habitacionais do município foram construídos com recursos do $\mathrm{BNH}$, estando estes localizados na zona norte de Londrina, direcionando uma lógica de crescimento urbano popular para essa região da cidade. $\mathrm{Na}$ verdade, essa foi uma estratégia do poder público para resolver o problema da moradia, com a construção de núcleos habitacionais gigantescos em terrenos distantes do centro da cidade e em localidades de baixo valor imobiliário, compostos por 1.000 unidades habitacionais cada um e todos naquela mesma região.

Percebe-se claramente que a produção habitacional passou a ocorrer em grande parte de modo segregado social e espacialmente para a região norte da cidade. Alves (1991), em sua dissertação de mestrado Dinâmica espacial de produção e reprodução da força de trabalho em Londrina - os conjuntos habitacionais, relata que a produção habitacional de interesse social inicialmente não se deu em razão da falta de áreas para edificação ou implantação de conjuntos habitacionais e loteamentos, mas de estratégia específica do poder público municipal em localizar os conjuntos habitacionais naquela área, bastante distante do centro da cidade e com enormes áreas vazias entre os conjuntos e a malha urbana. Consequentemente, os vazios urbanos passaram a ser fortemente valorizados, contribuindo ainda mais para a especulação imobiliária e interesses privados.

Ainda na década de 1980, embora existisse a oferta de moradias para população de menor poder aquisitivo, o acirramento dos conflitos sociais também ocorria para uma parcela da população que não conseguia habilitar-se a uma casa de conjunto habitacional. Nessa época, outra modalidade de moradia passou a existir em Londrina e de modo informal em terrenos de domínio público: os assentamentos urbanos, que são caracterizados por um conjunto de moradias de pequenas dimensões construídas de material improvisado e ou sobras de construção e com certa urbanização, mediante ruas, de água, energia elétrica e definição dos lotes, que têm como objetivo obter no futuro a 
regularização fundiária, tornando com o passar dos anos o assentamento legalizado no meio urbano.

Em suma, a década de 1980 representa, até o presente momento, o ápice da produção de unidades habitacionais no município, sendo que, ao mesmo tempo, este período foi intenso e deslocado das diretrizes de planejamento urbano. Nas décadas de 1990 e 2000, a produção habitacional foi expressivamente inferior, sendo retomada com força no início da década de 2010, porém, na roupagem dos anos 1980 . Ao se observar a trajetória da atuação do poder público local em relação à questão da moradia no município de Londrina, parece que se assiste ao mesmo espetáculo de 30 anos atrás. A tabela e gráfico abaixo apresentam a evolução da produção habitacional no município de Londrina, sendo claro no gráfico que a década de 1980 é o período expressivo da habitação.

Tabela 1 - Empreendimentos executados no município de Londrina com o número de famílias atendidas por regiões mais atendidas da cidade de Londrina e por década.

\begin{tabular}{|c|c|c|c|c|}
\hline Período & $\begin{array}{l}\text { Número } \\
\text { unidades } \\
\text { habitacionais }\end{array}$ & $\begin{array}{l}\text { Número de } \\
\text { Empreendimentos }\end{array}$ & Fontes de Recursos & $\begin{array}{r}\text { Regiões mais } \\
\text { Atendidas* }\end{array}$ \\
\hline Antes de 1970 & 228 & 1 & BNH/FGTS & Sul e Leste \\
\hline Década 1970 & 8.397 & 24 & BNH/FGTS & Norte e Sul \\
\hline Década 1980 & 15.197 & 44 & $\mathrm{BNH} / \mathrm{FGTS}$ & Norte e Sul \\
\hline Década 1990 & 6.482 & 34 & $\begin{array}{l}\text { BNH/FGTS/Próprios/ } \\
\text { PAIH/PROHAP/COHAPAR }\end{array}$ & Norte, Sul e Leste \\
\hline Década 2000 & 3.040 & 29 & $\begin{array}{l}\text { PSH/Próprios/HBB/OGU/ } \\
\text { PAR/Associativo/COHAPAR }\end{array}$ & $\begin{array}{r}\text { Leste, Norte, } \\
\text { Oeste e Noroeste }\end{array}$ \\
\hline Década 2010** & 4.199 & 16 & FGTS/ FAR/ FDS/ OGU/ FNHIS & Norte e Sul \\
\hline TOTAL & 37.543 & 148 & & \\
\hline
\end{tabular}

Fonte: Londrina (2014, p. 51-62), dados compilados pelos autores.

*O termo "regiões mais atendidas da cidade de Londrina" corresponde ao destaque para as regiões que receberam maior número de unidades habitacionais na década.

**Os dados obtidos se enquadram até o ano 2013. 
Gráfico 1 - Produção habitacional em Londrina por década.

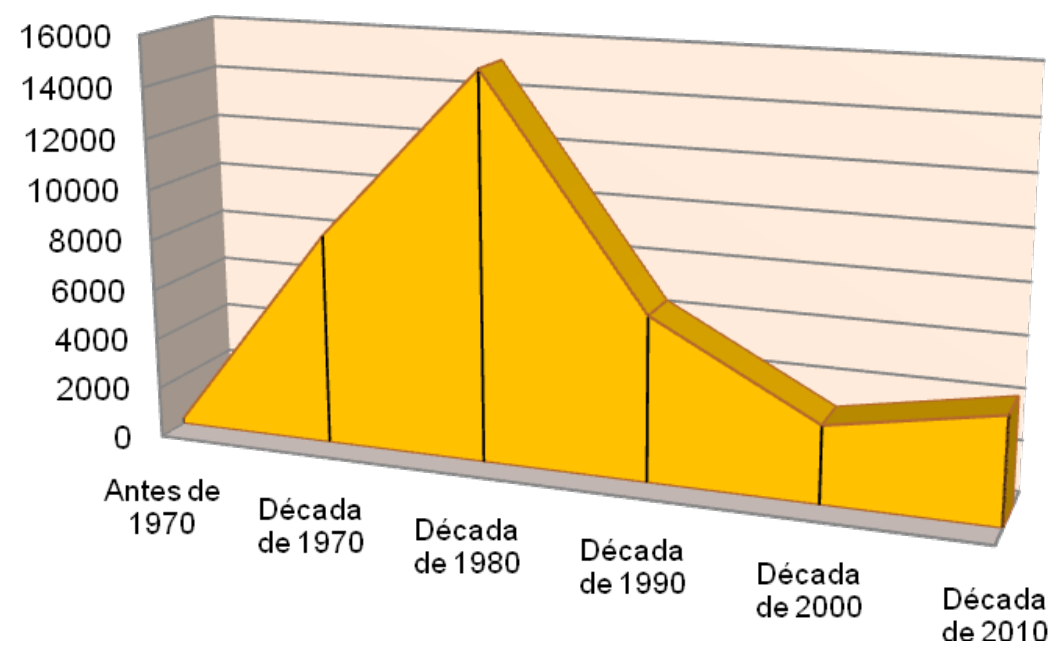

Fonte: Araujo Junior e Cordeiro (2015)

Já na tabela 2, tem-se o número de unidades habitacionais de Londrina no período de 2002 a 2013 organizados por programa habitacional, sendo que nesta é possível identificar que a maior quantidade de 3.560 moradias foi construída no município pelo Programa Minha Casa Minha Vida (PMCMV), o que representa um percentual expressivo de $47,6 \%$ do total.

Tabela 2 - Síntese dos dados habitacionais quanto aos empreendimentos executados entre os anos 2002 a 2013 no município de Londrina e número de famílias atendidas.

\begin{tabular}{lccl}
\hline Programa Habitacional & $\begin{array}{r}\text { Número de unidades } \\
\text { habitacionais }\end{array}$ & $\begin{array}{r}\text { Quantidade de } \\
\text { Empreendimentos }\end{array}$ & $\begin{array}{l}\text { Concentração de } \\
\text { regiões atendidas }\end{array}$ \\
\hline $\begin{array}{l}\text { Programa de Arrendamento } \\
\text { Residencial (PAR) }\end{array}$ & 2.330 & 16 & $\begin{array}{l}\text { Norte, Noroeste e } \\
\text { Leste }\end{array}$ \\
\hline $\begin{array}{l}\text { Associativo } \\
\text { Regularização } \\
\text { assentamentos precários }\end{array}$ & 11 & 1 & Leste \\
\hline $\begin{array}{l}\text { Programa Minha Casa Minha } \\
\text { Vida }\end{array}$ & 958 & 8 & Norte, Sul e Oeste \\
\hline $\begin{array}{l}\text { COHAPAR } \\
\text { TOTAL }\end{array}$ & 3.560 & 10 & $\begin{array}{l}\text { Norte, Noroeste, Sul } \\
\text { e Oeste }\end{array}$ \\
\hline
\end{tabular}

Fonte: Londrina (2014, p. 51-62), dados compilados pelos autores.

Na verdade, o PMCMV em Londrina tem resultado em urbanizações de grande impacto, pois só o Residencial Vista Bela com 2.712 moradias representa aproximadamente 76\% das 3.560 unidades habitacionais construídas pelo programa concentrado em uma única área da cidade, localizado nas proximidades com o meio rural e distante dos 
equipamentos sociais e da infraestrutrua urbana. A tabela, a seguir, mostra a distribuição das unidades habitacionais produzidas pelo Programa Minha Casa Minha Vida (PMCMV) em Londrina entre os anos 2009 a 2013.

Tabela 3 - Empreendimentos executados no município de Londrina pela COHAB-LD pelo Programa Minha Casa Minha Vida (PMCMV) - anos 2009 a 2013 com recursos do FGTS/ FAR/ FDS.

\begin{tabular}{crrr}
\hline \multirow{2}{*}{ Ano de entrega } & Região Atendida & Número de & Nome do empreendimento \\
\hline 2009 & Norte & 32 & Elizabeth \\
\hline 2010 & Noroeste & 85 & Ana Terra \\
\hline 2010 & Sul & 100 & Nova Esperança I \\
\hline 2011 & Sul & 50 & Nova Esperança II \\
\hline 2011 & Oeste & 21 & Columbia I \\
\hline 2011 & Sul & 02 & Santa Joana \\
\hline 2011 & Norte & 2.712 & Vista Bela I,II,III,IV,V,VI,VII,VIII,IX,X \\
\hline 2012 & Leste & 18 & Vila Romana \\
\hline 2012 & Sul & 60 & Maravilha \\
\hline 2013 & Sul & 480 & Cristal , I, II \\
\hline TOTAL & & 3.560 & 10 Empreendimentos
\end{tabular}

Fonte: COHAB-LD (2014), dados compilados pelos autores.

Logo, dentro do panorama da política nacional de habitação de interesse social, o PMCMV tornou-se um programa populista, e, portanto, não é permanente, muda conforme o grupo político no poder, e deixa de afirmar a regionalidade, como se o Brasil fosse feito a partir das grandes capitais. Nesse sentido, o programa não atenta para a diversidade, integração e desenvolvimento das médias e principalmente das pequenas cidades, no qual assistimos novas formas travestidas de velhos processos de socialização de custos, especulação imobiliária e atuação de gestores descomprometidos com a população.

Quanto aos programas habitacionais empreendidos no município, de 1970 até 2001 foi computado um total de 35.515 moradias construídas em Londrina com diversas fontes de recursos: BNH - Banco Nacional de Habitação; Prefeitura Municipal/ COHAB-LD; CEF Caixa Econômica Federal; COHAPAR - Companhia de Habitação do Paraná; Poupalar e Próprios, segundo o documento PEMAS - Plano Estratégico Municipal para Assentamentos Subnormais (COHAB-LD, 2002). No entanto, esse número ainda não atendeu a população, 
visto que hoje, de acordo com a COHAB-LD, o número de inscritos já chega a quase de 59 mil (LONDRINA, 2014).

\section{O caso do Residencial Vista Bela em Londrina}

O Residencial Vista Bela é um conjunto habitacional, localizado no bairro censitário Perobinha, na região a extremo norte da cidade de Londrina-PR, próximo ao limite com o Município de Cambé e nas imediações da região dos Cinco Conjuntos, área de habitação popular que surgiu na década de 1980. O residencial foi construído no início da década de 2010 e entregue em etapas, primeiramente no ano de 2011 e depois o restante em 2012 como aplicação da política nacional pelo Programa Minha Casa Minha Vida (PMCMV).

Atualmente, a estimativa de população residente no Vista Bela é de aproximadamente 12 mil habitantes. A figura a seguir mostra uma vista geral dos empreendimentos habitacionais do Residencial Vista Bela.

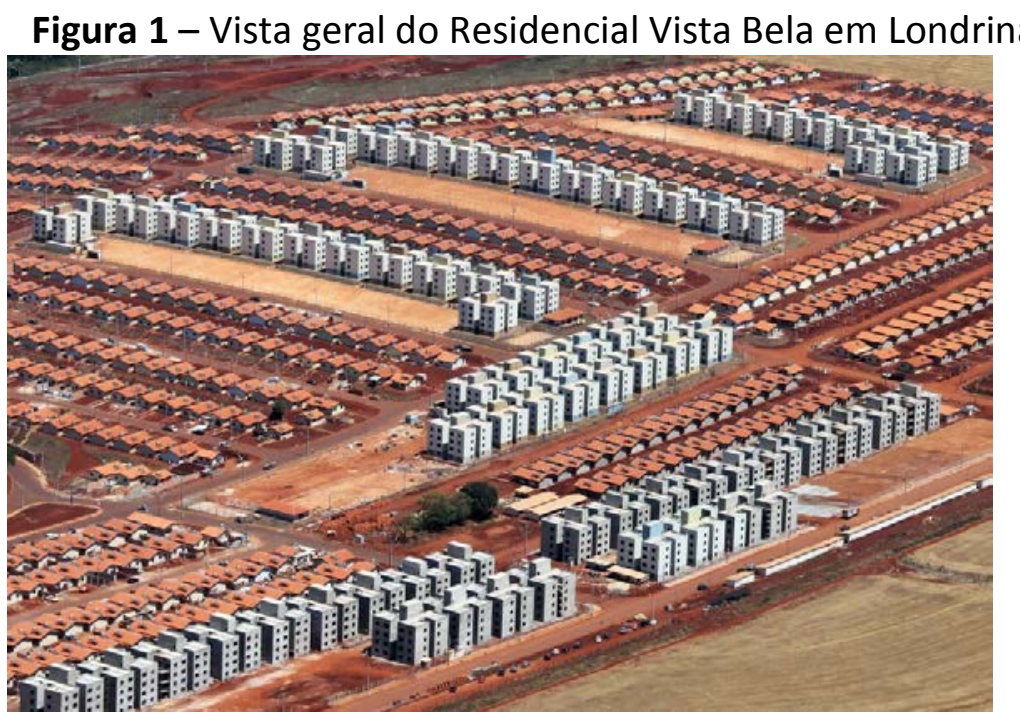

Fonte: Protenge Engenharia (2012)

Os principais acessos ao Residencial Vista Bela são pela Avenida Saul Elkind indo na direção oeste até a Rua André Buck e pela Avenida Graciliano Ramos até a Rua Ildo Garcia no Jardim Ana Terra, com prolongamento de via sobre o fundo de vale do Ribeirão Lindoia. A figura abaixo mostra a localização do Residencial Vista Bela na cidade de Londrina. 
Figura 2 - Mapa da cidade de Londrina e localização do Residencial Vista Bela

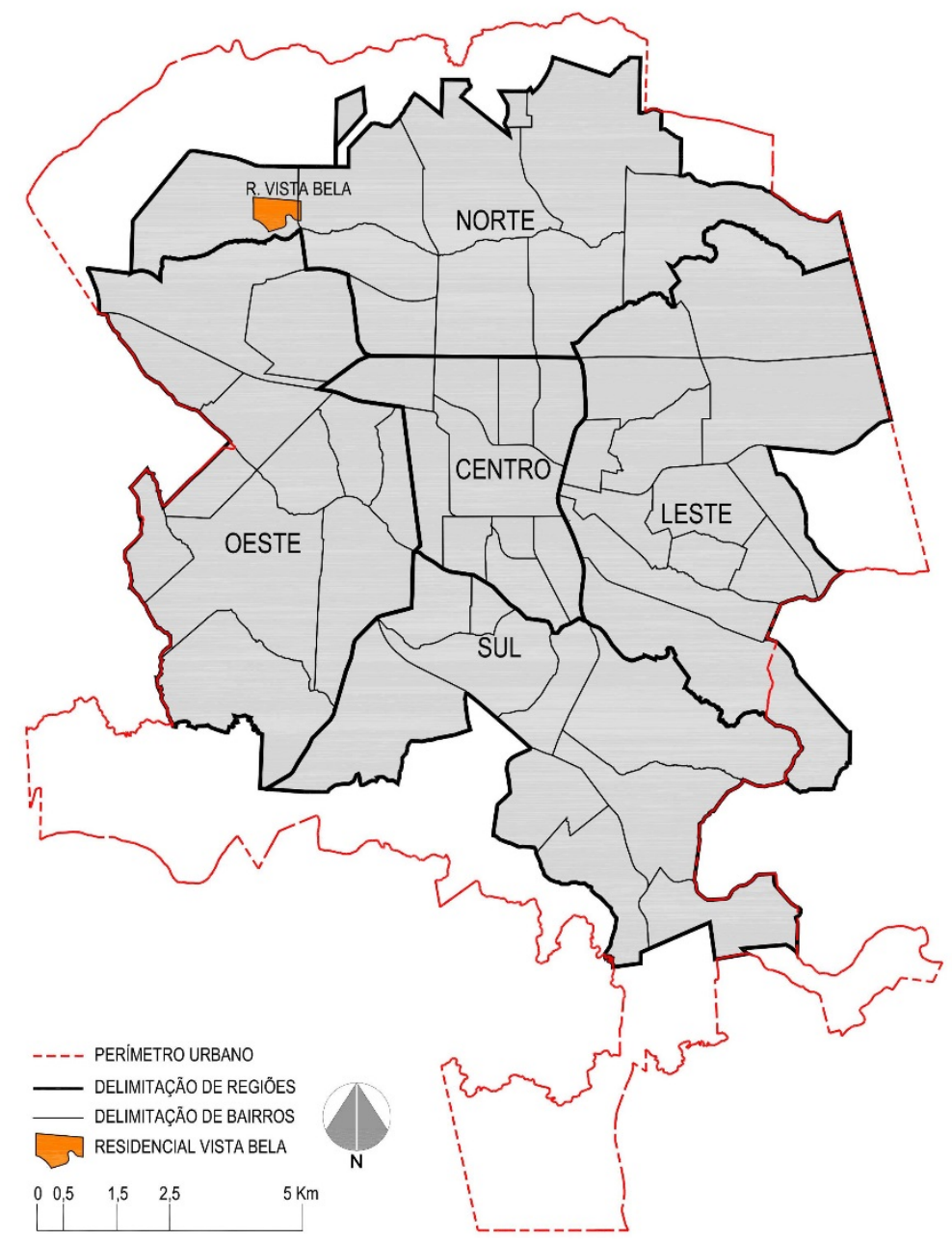

Fonte: Araujo Junior e Cordeiro (2015), base de dados IPPUL (Instituto de Pesquisa e Planejamento Urbano de Londrina)

De acordo com o IBGE (2010), o bairro Perobinha na zona norte em Londrina possuía no ano do Censo Demográfico de 2010 somente 2 setores censitários (003 e 004) e uma pequena população residente de 26 habitantes em 8 domicílios. Isso confirma que a região onde foi implantado o Residencial Vista Bela constituía uma vasta área de expansão urbana dentro da cidade de Londrina, permeada por intensa atividade agrícola, ao passo que também estava desprovida de qualquer infraestrutura urbana. De modo geral, o relevo da região é favorável à urbanização em razão dos topos suaves e baixos percentuais de declividade, porém, no caso do Residencial Vista Bela, a porção inferior do terreno, onde está grande parte das casas geminadas, é caracterizada por áreas de declive mais acentuado, o que ocorre já nas proximidades com o fundo de vale do Córrego do Topo e Ribeirão Lindoia. As figuras, a seguir, mostram o processo de implantação do Residencial 
Vista Bela, sendo que na área ao final da década de 2000 havia pouca incidência de ocupação urbana. A paisagem comum da região é de cultivo agrícola, comum às áreas de expansão urbana. Nota-se também a proximidade com os cursos hídricos.

Figura 3 - Registro da implantação do Residencial Vista Bela.
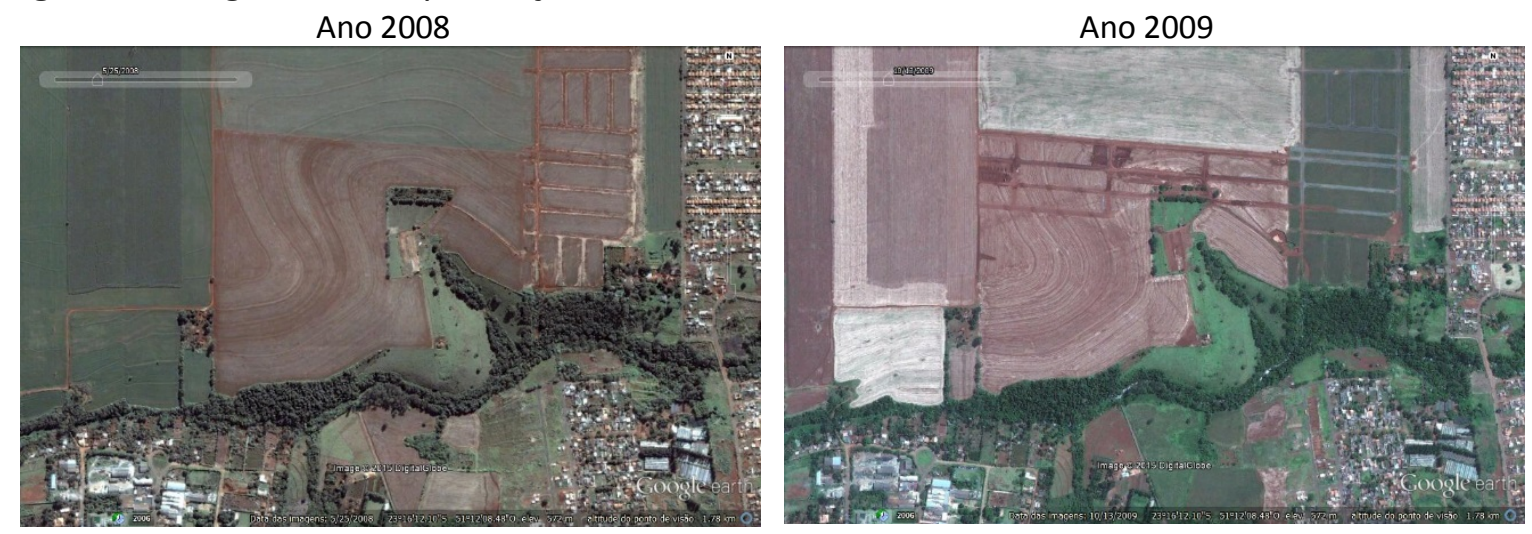

Ano 2011

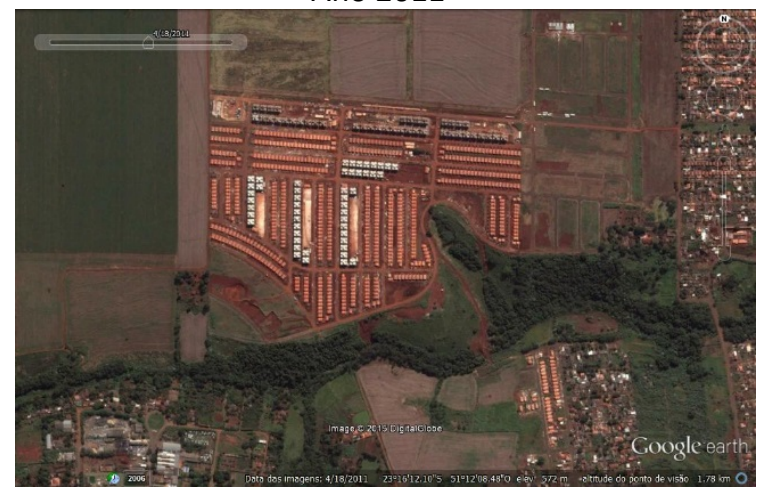

Ano 2015

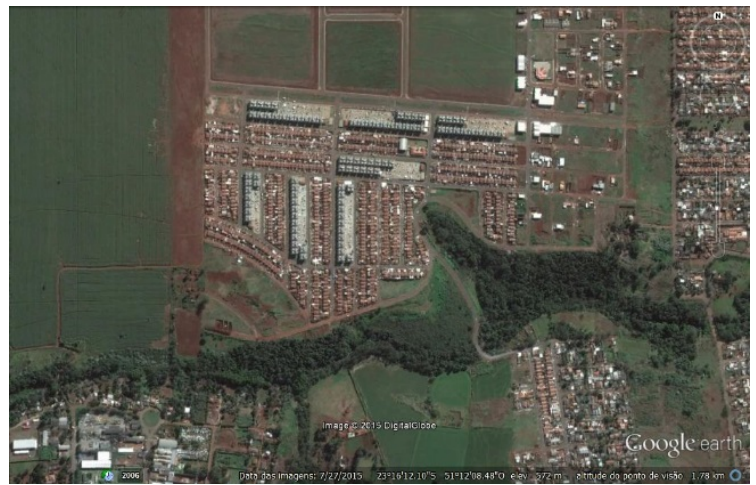

Fonte: Google Earth.

A sua população foi formada a partir da seleção de moradores de diferentes assentamentos precários localizados em diversas regiões na cidade de Londrina, sendo que tais moradores foram distribuídos em 31 quadras, 17 ruas, 90 blocos de apartamentos e 0 restante em residências unifamiliares geminadas, constituindo praticamente uma pequena cidade dentro da cidade de Londrina. De acordo com dados do Perfil do Município (LONDRINA, 2014), no Residencial Vista Bela foram viabilizados pela COHAB-LD o total de 2.712 moradias sociais, distribuídas em 10 empreendimentos habitacionais, sendo 1.272 casas e 1.440 apartamentos, como mostra a tabela abaixo. 
Tabela 4 - Empreendimentos habitacionais do Residencial Vista Bela em Londrina-PR

\begin{tabular}{|c|c|c|c|c|}
\hline $\begin{array}{l}\text { Empreendimentos } \\
\text { Habitacionais }\end{array}$ & $\begin{array}{l}\text { Ano de } \\
\text { Entrega }\end{array}$ & $\begin{array}{l}\text { Número de unidades } \\
\text { habitacionais (casas) }\end{array}$ & $\begin{array}{l}\text { Número de unidades } \\
\text { habitacionais (apartamentos) }\end{array}$ & $\begin{array}{l}\text { Procedência } \\
\text { dos recursos }\end{array}$ \\
\hline Vista Bela I & 2011 & 305 & 0 & FAR/OGU \\
\hline Vista Bela II & 2011 & 0 & 208 & FAR/OGU \\
\hline Vista Bela III & 2011 & 0 & 208 & FAR/OGU \\
\hline Vista Bela IV & 2011 & 431 & 0 & FAR/OGU \\
\hline Vista Bela V & 2011 & 0 & 224 & FAR/OGU \\
\hline Vista Bela VI & 2012 & 536 & 0 & FAR/OGU \\
\hline Vista Bela VII & 2011 & 0 & 144 & FAR/OGU \\
\hline Vista Bela VIII & 2012 & 0 & 224 & FAR/OGU \\
\hline Vista Bela IX & 2012 & 0 & 224 & FAR/OGU \\
\hline Vista Bela X & 2012 & 0 & 208 & FAR/OGU \\
\hline TOTAL & & 1.272 & 1.440 & \\
\hline
\end{tabular}

Fonte: COHAB-LD (2014), dados compilados pelos autores.

Ainda que o Programa Minha Casa Minha Vida tenha restrições quanto ao número de unidades habitacionais, visando evitar a tendência de grandes aglomerações, os idealizadores do Residencial Vista Bela usaram a estratégia de formar um consórcio e dividir a gleba para contornar as condições exigidas pelo programa. Assim, o empreendimento ultrapassou o limite de 500 unidades habitacionais, obtendo um máximo de aproveitamento das áreas, reduzindo custos e, consequentemente, obtendo maior lucro, a partir da estandardização da produção, como destacam Cardoso e Aragão (2013) numa reflexão após o fim do BNH (Banco Nacional da Habitação) na década de 1980 e o atual processo de aplicação dos programas habitacionais no Brasil, como Programa Minha Casa Minha Vida.

[...] para poder viabilizar a racionalização do processo produtivo, será necessário ampliar a escala dos empreendimentos e também investir na estandardização. [...] Para enfrentar esse problema, a regulamentação do programa propunha um limite de 500 unidades por empreendimento. No entanto, os empreendedores resolveram facilmente esse problema ao subdividir os megaempreendimentos, aprovando projetos em terrenos contíguos, mas com as mesmas tipologias arquitetônicas, soluções construtivas e implantação nos terrenos (CARDOSO; ARAGÃO, 2013, p. 54-55).

O Residencial Vista Bela em Londrina foi um dos primeiros empreendimentos do Programa Minha Casa Minha Vida (PMCMV), e o maior em número de unidades habitacionais que, em quatro anos após sua entrega para a população, acumula problemas e denúncias de toda natureza, como deficiências construtivas das unidades habitacionais, 
terrenos e unidades habitacionais incompatíveis com a realidade das famílias numerosas, comercialização e especulação imobiliária na região, violência no bairro, falta de oportunidades de emprego na localidade e falta de infraestrutura urbana e serviços de atendimento à população, entre outros. Os depoimentos abaixo são de moradores do Residencial e ilustram a condição vivida por eles:

Problemas estruturais também são comuns no dia a dia dos moradores do Vista Bela. Há falta de água frequente e infiltrações, direto está entupindo algum cano. Por causa das infiltrações, já tivemos que pintar o condomínio inteiro de novo, assinala o vendedor autônomo ${ }^{3}$ fiscal do condomínio Vista Bela VIII.

Com seis pessoas, a familia de uns dos moradores ${ }^{4}$ se vira como pode para se acomodar nos 37 metros quadrados da casa nova no Residencial Vista Bela, em Londrina (Norte do estado). A posse de tão poucos móveis, antes motivo de desgosto, se tornou vantagem na hora de colocar tudo no imóvel entregue há três meses pelo programa Minha Casa Minha Vida. A falta de recursos não permite a ampliação da casa e, mesmo se o dinheiro estivesse à disposição, não seria possível fazer muita coisa. O que sobra dos $125 \mathrm{~m}^{2}$ do terreno é muito pouco.

As áreas urbanizadas e providas de equipamentos urbanos e sociais estão distantes do residencial, o que tornou a ocupação inicial difícil para a população. As localidades mais próximas que servem de suporte são o Jardim Pandovani, Newton Guimarães, Conjunto Habitacional José Giordano e o bairro Parigot de Souza. A localização da implantação do Residencial Vista Bela colaborou para a formação de novos vazios urbanos, principalmente ao longo dos eixos de infraestrutura, atualmente ligados ao valor da terra para fins de especulação imobiliária. O uso essencialmente residencial previsto para o Vista Bela tornou a localidade custosa até mesmo para atividades rotineiras ligadas ao comércio e serviços locais, fazendo com que a população dependesse de deslocamentos até mesmo para os afazeres diários, assim como a distância do emprego e outras atividades, tornou a localidade em um "bairro dormitório". Portanto, o Residencial Vista Bela está longe da maior parte da população londrinense e desconectado das políticas públicas como educação, saúde, segurança, lazer e trabalho. Além disso, a região não estava preparada para receber tamanha demanda, principalmente, dos serviços públicos que não conseguem

\footnotetext{
${ }^{3}$ Entrevista concedida ao Jornal de Londrina em 14 de fevereiro de 2014 (LUCIANO; MARCHIORI, 2014).

${ }^{4}$ Entrevista concedida ao jornal Gazeta do Povo no dia 6 de outubro de 2011 (GONÇALVES, 2011).
} 
minimamente atender às necessidades dos moradores. Tais políticas de desenvolvimento econômico mostram que sua base está alicerçada na manutenção das desigualdades sociais, refletindo-se no espaço urbano por meio das múltiplas expressões de segregação espacial e exclusão socioterritorial dos bairros populares e periferias da cidade. A figura a seguir mostra a localização do Residencial Vista Bela nas franjas da cidade e a distância da oferta de equipamentos sociais. Mesmo tendo consciência dos impactos, a municipalidade não elaborou nenhum estudo de impacto na vizinhança.

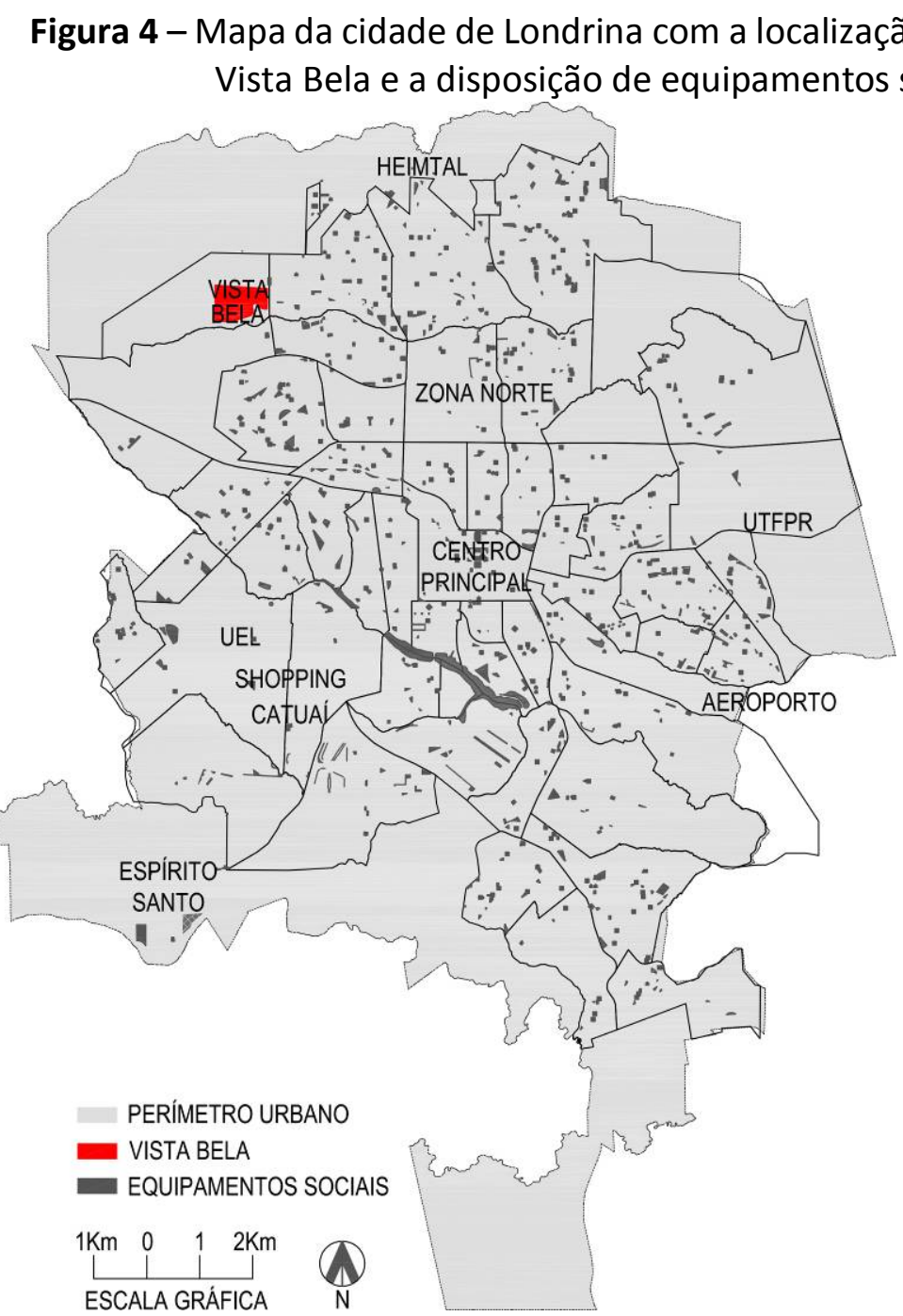

Fonte: Araujo Junior e Cordeiro (2015), base de dados IPPUL (Instituto de Pesquisa e Planejamento Urbano de Londrina)

Outros aspectos ainda podem ser apontados nesta aplicação da política do Programa Minha Casa Minha Vida (PMCMV) em Londrina, como a composição pela procedência das 
famílias. O mega empreendimento do Residencial Vista Bela atendeu não só à região norte de Londrina, mas também absorveu a demanda habitacional de outras regiões da cidade, compondo ao final, famílias de diferentes procedências, sendo esta em grande parte moradora de fundos de vale e de características distintas. Esse fato tem sido uma dificuldade apontada e que tem gerado a não fixação das pessoas nesse local que preferem retornar a sua localidade de origem e retomar sua inserção, mesmo que em condições de risco. A tabela abaixo mostra a composição e procedência das famílias do Residencial Vista Bela pelas regiões na cidade de Londrina.

Tabela 5 - Síntese dos dados da composição de procedência das famílias do Residencial Vista Bela em Londrina-PR.

\begin{tabular}{lcc}
$\begin{array}{l}\text { Regiões da Cidade de } \\
\text { Londrina }\end{array}$ & Número Total de Famílias & $\begin{array}{r}\text { Número de Localidades } \\
\text { em cada Região }\end{array}$ \\
\hline Zona Norte & 1.723 & 67 \\
\hline Zona Leste & 556 & 52 \\
\hline Zona Oeste & 171 & 33 \\
\hline Zona Sul & 21 & 6 \\
\hline Centro & 241 & 12 \\
\hline TOTAL & $\mathbf{2 . 7 1 2}$ & $\mathbf{1 7 0}$ \\
\hline
\end{tabular}

Fonte: Araujo Junior e Cordeiro (2015)

O território, segundo Haesbaert (1997), sempre envolve, ao mesmo tempo, a dimensão simbólica, cultural, por meio de uma identidade territorial atribuída pelos grupos sociais como forma de controle simbólico sobre o espaço onde vivem. Nesse sentido, a apropriação do espaço que se constata no Residencial Vista Bela é uma apropriação de caráter político disciplinar, de dominação, de coordenação do espaço como forma de domínio e disciplinarização dos indivíduos. Quando o Estado define, por meio de seus programas habitacionais, o espaço que será ocupado por esses conjuntos e seleciona quem irá neles habitar, de certa forma está disciplinando, engessando, direcionando, obscurecendo a vida desses sujeitos, fazendo-os decidir onde e como morar. O gráfico e o mapa a seguir mostram melhor a procedência das famílias do Residencial Vista Bela. 
Gráfico 2 - Proporção na composição da procedência das famílias do Residencial Vista Bela em Londrina-PR

NÚMERO TOTAL DE FAMÍLIAS

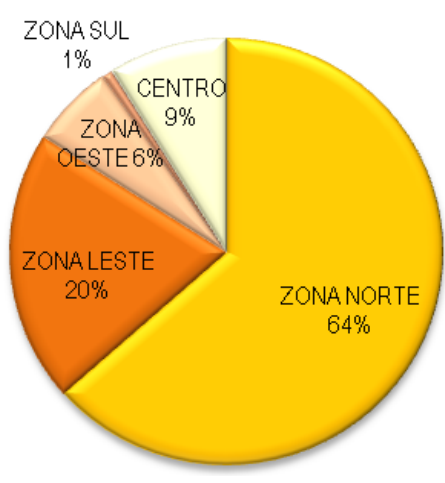

NÚMERO DE LOCALIDADES

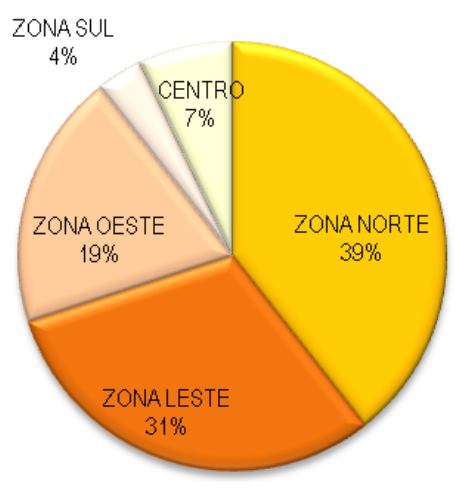

Fonte: Araujo Junior e Cordeiro (2015)

Figura 5 - Mapa de procedência das famílias do Residencial Vista Bela em Londrina

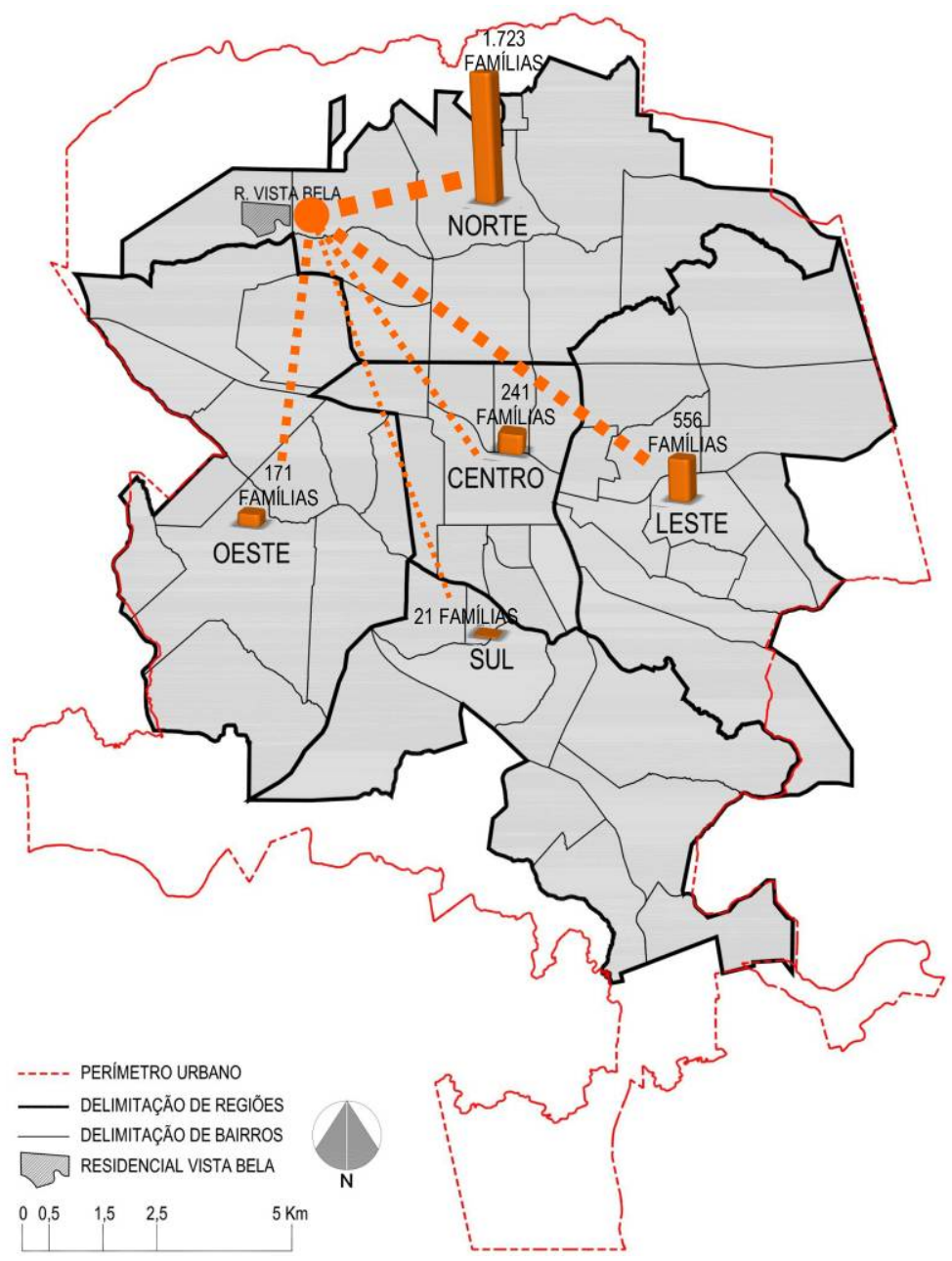

Fonte: Araujo Junior e Cordeiro (2015), base de dados IPPUL (Instituto de Pesquisa e Planejamento Urbano de Londrina) 
Várias famílias passaram por essa condição de aceitar a imposição do projeto do Residencial Vista Bela. Destaca-se aqui a entrevista concedida por uma ex-moradora, que relata como foi realizada a seleção para o empreendimento no município de Londrina. Para as pessoas, esses territórios traduzem o sentido que o lugar traz, ou seja, as vivências, as trocas e interações, a luta, a conquista de sobrevivência cotidiana.

A mesma atitude que eu tive, várias pessoas também tiveram, não fui eu só. $\mathrm{Na}$ minha rua cinco famílias saíram da casa porque não aguentaram viver daquele modo, o jeito como eles fizeram. (Ex-moradora ${ }^{5}$ do Residencial - 2015).

A partir dessa fala, identificam-se outras famílias que abandonaram suas casas no Residencial Vista Bela e em outros empreendimentos do PMCMV em Londrina, e que tiveram a atitude de retornar aos seus locais de origem. Em uma reportagem ${ }^{6}$ veiculada no jornal Folha de Londrina (OGAWA, 2014), as famílias que desistiram das casas alegaram, entre vários motivos, a falta de infraestrutura no bairro, a condição de estarem expostas à violência, além da não adaptação ao novo local, optando, assim, por retornar aos fundos de vale. A mesma reportagem ainda mostra a história de uma família que deixou o Residencial Vista Bela para morar numa pequena casa no Assentamento Santa Fé, na zona leste de Londrina. O casal diz possuir sete filhos e que, no bairro onde foram morar, não tinha infraestrutura para os atendimentos, principalmente escolas e creches. Portanto, o casal revelou na entrevista que vendeu a unidade habitacional do Residencial Vista Bela e que retornou a região leste, onde residia anteriormente. Os atuais moradores relatam que quando procuram assistência médica não encontram, e que para chegar ao posto de saúde andam cerca de 40 minutos, para depois ter ainda de entrar na fila de espera para ser atendido. Uma moradora relatou, para a entrevista do jornal, que sua filha mais nova nasceu em casa e sem assistência, pois quando chamou o serviço móvel (ambulância) às $5 \mathrm{~h}$ da manhã, este só chegou às $7 \mathrm{~h}$.

O Residencial Vista Bela é a prova concreta da falta de integração das políticas urbanas e sociais e da ausência da produção habitacional com ênfase no direito à cidade.

\footnotetext{
${ }^{5}$ Entrevista concedida para tese de doutorado (CORDEIRO, 2015).

${ }^{6}$ Reportagem veiculada na Folha de Londrina, no dia 21 de março de 2014, traz o título: “Mutuários desistem da casa", e o subtítulo: "Moradores reclamam da falta de estrutura em bairros novos e dizem que preferem voltar a viver nos fundos de vale" (OGAWA, 2014).
} 
Os conjuntos habitacionais continuam sendo construídos em locais distantes como os antigos conjuntos do BNH (Banco Nacional da Habitação) dos anos 1960 a 1980, ao passo que os governos municipais não enfrentam a situação e ignoram as políticas integradoras de ordenamento territorial. Os moradores dizem que têm casa, mas que a cidade não vem junto. Ao analisar outros programas habitacionais na conjuntura atual, percebe-se que esses dialogam melhor com outras políticas. No Programa Minha Casa Minha Vida não há esse diálogo, estando restrito aos interesses do capital, já que, neste caso, as empresas da construção civil ${ }^{7}$ são as que propõem os empreendimentos habitacionais para o município.

É sabido que os problemas urbanos não terminam na construção da casa, a luta pelo direito à moradia é também a luta pelo acesso aos demais serviços públicos, que possam garantir minimamente a necessidade da população. Dessa forma, o bairro em questão pode ser encarado como mais uma experiência de omissão do poder público local no trato das políticas públicas.

\section{Considerações finais}

Nas últimas décadas, o Brasil passou por um acelerado processo de urbanização, o que acarretou um quadro de deficiência no que diz respeito ao desenvolvimento urbano, com déficit elevado em saneamento, infraestrutura e habitação, atingindo com maior intensidade os segmentos da população de menor poder aquisitivo, agravado pela desproporcionalidade na distribuição de renda e na destinação de recursos públicos.

Do ponto de vista da produção de seu espaço, nossas cidades estão nas subordinações absolutas à lógica dos negócios. Segundo Rolnik (1995), a lógica capitalista é que define as prioridades e os parâmetros de utilização da cidade, sendo que essas prioridades são legitimadas e administradas pelo Estado, que passa a transformar o espaço urbano e as relações estabelecidas entre seus habitantes em mercado. O Residencial Vista Bela, visto como o maior canteiro de obras do Programa Minha Casa Minha Vida na época de sua construção, na verdade representa a condução da cidade para o favorecimento do capitalismo mediante investimentos e intervenções realizadas no espaço urbano. Esse

\footnotetext{
${ }^{7}$ De acordo com a reportagem do Jornal de Londrina (BRIGUET, 2011), o gestor municipal afirma que "não faltou planejamento" [...] "A construção do Vista Bela é de responsabilidade da iniciativa privada, as construtoras: Protenge, Terra Nova e Artenge e o projeto passou por análise da Caixa Econômica Federal".
} 
empreendimento afronta os requisitos mínimos do direito à moradia adequada apontados pela ONU - Organização das Nações Unidas, sendo incoerente e contraditório por acumular milhares de pessoas em um espaço com deficiência de equipamentos e serviços públicos. Neste sentido, tem-se que a avaliação da referida "política habitacional" é negativa, em que pese as entrevistas iniciais indicarem a intenção de permanência no local, a despeito da privação dos serviços e equipamentos apontados acima.

Na perspectiva de David Harvey (2006), o Estado capitalista não pode ser outra coisa que instrumento de dominação de classe, pois se organiza para sustentar a relação básica entre capital e trabalho. Percebe-se que a produção da urbanização contemporânea expande a acumulação fundiária urbana por meio da valorização imobiliária de áreas antes desvalorizadas, o que se pretendeu demonstrar neste artigo.

\section{Referências}

ALVES, C. Dinâmica espacial de produção e reprodução da força de trabalho em Londrina: os conjuntos habitacionais. 1991. Dissertação (Mestrado em Geografia) - Departamento de Geografia da FFLCH, Universidade de São Paulo, São Paulo, 1991.

ARAUJO JUNIOR, M. E. de; CORDEIRO, S. M. A. Direito à Moradia: aplicabilidade e efetividade dos instrumentos jurídicos na Região Metropolitana de Londrina/PR. Londrina, 2015. (Projeto de Pesquisa n. 07951 pelo Departamento de Direito Público CESA-PUB - Universidade Estadual de Londrina).

ARRETCHE, M. T. S. Federalismo e relações intergovernamentais no Brasil: a reforma de Programas Sociais. Revista de Ciencias Sociais, Rio de Janeiro, v. 45, n. 3 p. 431- 458, 2002.

BONDUKI, N. G. Origens da habitação social do Brasil. São Paulo: Estação Liberdade, 1998.

BRASIL. Lei no. 11.977, de 7 de julho de 2009. Dispõe sobre o Programa Minha Casa, Minha Vida - PMCMV e a regularização fundiária de assentamentos localizados em áreas urbanas; altera o Decreto-Lei no. 3.365, de 21 de junho de 1941, as Leis nos. 4.380, de 21 de agosto de 1964, 6.015, de 31 de dezembro de 1973, 8.036, de 11 de maio de 1990, e 10.257, de 10 de julho de 2001, e a Medida Provisória no. 2.197 -43, de 24 de agosto de 2001; e dá outras providências. Diário Oficial da União, Brasília, DF, 8 jul. 2009. Seção 1, p. 2-6.

BRIGUET, P. Minha casa. E minha escola? Jornal de Londrina, Londrina, 11 dez. 2011. Caderno Habitação. Disponível em: $<$ http://www.jornaldelondrina.com.br/edicaododia/conteudo.phtml?t|=1\&id=1201629\&t it=Minha-casa-E-minha-escola $>$. Acesso em: 5 jun. 2015. 
CARDOSO, A. L.; ARAGÃO, T. A. Do fim do BNH ao programa minha casa minha vida: 25 anos da política habitacional no Brasil. In: CARDOSO, A. L. (Org.). O Programa minha casa minha vida e seus efeitos territoriais. Rio de Janeiro: Letra Capital, 2013. p. 17-66.

COHAB-LD, Companhia de Habitação de Londrina. PEMAS: plano estratégico municipal para assentamentos subnormais. Londrina: COHAB-LD, 2002.

Ofício COHAB-LD/ DIRETORIA TÉCNICA/ 0793/2014. Londrina, 22 maio 2014.

CORDEIRO, S. M. A. Obliterações do direito à moradia na política habitacional de interesse social do Município de Londrina - PR. 2015. 288 f. Tese (Doutorado em Serviço Social) Universidade Estadual de Londrina, Londrina, 2015.

DAMBROS, M. F. O aluguel social como expressão do déficit habitacional no maciço do Morro da Cruz - Florianópolis/SC: desafios ao serviço social. 2014. 78 f. Trabalho de Conclusão de Curso (Graduação em Serviço Social) -Universidade Federal de Florianópolis, Florianópolis, 2014.

ENGELS, F. Para a questão da habitação. Moscovo: Progresso, 1982. Disponível em: <https://www.marxists.org/portugues/marx/1873/habita/>. Acesso em: 20 abr. 2015.

FAORO, R. Os donos do poder: formação do patronato político brasileiro. 3. ed. Porto Alegre: Globo, 2001.

FERREIRA, J. S. W.; UEMURA, M. Política urbana. In: DENALDI, R. (Org.). Ações integradas de urbanização de assentamentos precários. Brasília: Ministério das Cidades, 2009.

GONÇALVES, J. Casas populares "encolhem". Gazeta do Povo, Curitiba, 6 out. 2011. Caderno Vida e Cidadania. Disponível em: <http://www.gazetadopovo.com.br/vida-ecidadania/casas-populares-encolhem-9mos865fmuliwrzzp1k88vbda $>$. Acesso em: 8 set. 2015.

HAESBAERT, R. Des-territorialização e identidade: a rede "gaúcha" no nordeste. Niterói: EDUFF, 1997.

HARVEY, D. A produção capitalista do espaço. São Paulo: Annablume, 2006.

IBGE. Sinopse preliminar do censo demográfico de 1980. Rio de Janeiro, 1983. . Censo demográfico 2010. Rio de Janeiro, 2010.

LONDRINA. Prefeitura Municipal. Perfil do município de Londrina - 2014 (ano-base 2013). Londrina: Prefeitura Municipal de Londrina, 2014.

LUCIANO, A.; MARCHIORI, R. Moradias populares de Londrina ganham puxadinhos para comércio. Jornal de Londrina, Londrina, 14 fev. 2014. Caderno Brasil. Disponível em: $<$ http://www.jornaldelondrina.com.br/brasil/conteudo.phtml?tl=1\&id=1447159\&tit=Mor adias-populares-de-Londrina-ganham-puxadinhos-para-comercio $>$. Acesso em: 8 set. 2015. 
MARICATO, E. Brasil, cidades: alternativas para a crise urbana. 3. ed. Rio de Janeiro: Vozes, 2008.

. Os impasses da política urbana no Brasil. Petrópolis: Vozes, 2011.

OGAWA, V. Mutuários desistem de casas em Londrina. Folha de Londrina, Londrina, 21 mar. 2014. Caderno Cidades. Disponível em: <http://www.folhaweb.com.br/?id_folha=21--2525-20140321>. Acesso em: 3 set. 2015.

PELEGRINO, A. I. C. Vida cotidiana em favelas do Rio de Janeiro: habitação, trabalho e família. 2003. $381 \mathrm{f}$. Tese (Doutorado em Planejamento Urbano e Regional) Universidade Federal do Rio de Janeiro, Rio de Janeiro, 2003.

PROTENGE ENGENHARIA. Residencial Vista Bela: Loteamento Aberto, 2012. Disponível em: <http://www.protengeengenharia.com.br/obras/371/residencial-vista-bela/londrinapr>. Acesso em: 10 nov. 2015.

ROLNIK, R. O que é cidade. São Paulo: Brasilense, 1995.

SANTOS, M. Espaço e método. São Paulo: Nobel, 1985.

VALENÇA, M. Globabitação: sistemas habitacionais no Brasil, Grã-Bretanha e Portugal. São Paulo: Terceira Margem, 2001. 